\title{
Ciliated hepatic foregut cyst: a report of 6 cases and a review of the English literature
}

\author{
Katherine C. Bishop ${ }^{1,2}$, Carmen M. Perrino ${ }^{3 *}$, Marianna B. Ruzinova ${ }^{3}$ and Elizabeth M. Brunt ${ }^{3}$
}

\begin{abstract}
Background: Ciliated hepatic foregut cyst (CHFC) is a rare cystic lesion most commonly identified in segment 4 of the liver that arises from the embryonic foregut. The classic histologic pattern is comprised of 4 distinct layers (inner ciliated epithelial lining, smooth muscle, loose connective tissue, fibrous capsule). Although rare, cases of metaplastic and malignant epithelial lining have been described in CHFC.

Methods: We report 6 additional cases of CHFC, one of which had gastric metaplasia of the cyst lining, and review all reported cases of CHFC in the English literature. We describe the clinicopathologic analysis of 6 cases, with selective immunohistochemical analysis on 1 case with gastric metaplasia.

Results: Cases occurred in 4 women and 2 men (average age 55 years, range 42 to 67 years). Cysts ranged in size from 0.7 to $17 \mathrm{~cm}$ (average $7.2 \mathrm{~cm}$ ) and were grossly tan-pink to white with blood-filled contents. The majority were located in segment 4 of the liver, however 2 were located in the porta hepatis. Tumor serologies (CA19-9 and/or CEA) were performed in 3 cases; 1 case demonstrated elevated CA19-9, and 2 cases had laboratory values within normal limits. All cases showed the classic histologic findings, however one case additionally had extensive gastric metaplasia.

Conclusions: In conclusion, CHFC is a rare diagnostic entity that should be considered in the differential diagnosis for cystic hepatic lesions, particularly those located in segment 4 of the liver. Metaplasia and squamous carcinoma can occur, therefore complete surgical excision is the recommended treatment.
\end{abstract}

Keywords: Ciliated hepatic foregut cyst, Liver, Cyst

\section{Background}

Ciliated hepatic foregut cysts (CHFC) are rare cystic lesions of embryological origin that have been increasingly diagnosed in the last few decades [1]. Wheeler and Edmondson first coined this term and described its defining characteristics in 1984 [2]. CHFCs typically consist of four layers: (1) an inner layer of ciliated, pseudostratified columnar epithelium; (2) loose lamina propria; (3) a smooth muscle band, ranging from one to three layers in thickness; and (4) an outer fibrous capsule [3]. The cysts are often small (measuring less than $4 \mathrm{~cm}$ ), unilocular, subcapsular, and located in segment 4

\footnotetext{
* Correspondence: cperrino@path.wustl.edu

${ }^{3}$ Department of Pathology and Immunology, Washington University School of Medicine, Campus Box 8118, 660 South Euclid Avenue, Saint Louis, MO 63110, USA

Full list of author information is available at the end of the article
}

of the left lobe of the liver $[3,4]$. They are frequently discovered incidentally and are usually benign. While no reports exist of recurrence following complete surgical excision, CHFC has been reported to enlarge over time following biopsy and may recur after sclerotherapy [5-8].

The esophagus and trachea form from the dorsal foregut, while the liver forms from the ventral foregut; the similar features of CHFC compared to bronchial and esophageal cysts are presumably due to this common derivation of the liver, esophagus, and tracheobronchial tree from the embryological foregut [3]. There are no other known entities that are primary to the liver and have ciliated epithelium, thus distinguishing CHFC from other hepatic cysts [2].

Over one hundred cases of CHFC have been reported to date in the world literature [4]. Among these cases, 
six developed squamous metaplasia without evidence of dysplasia or malignancy and five developed squamous cell carcinoma of the innermost cyst lining [7, 9-19]. One case showed both evidence of gastric antral metaplasia and squamous cell carcinoma [16]. While metaplasia within a CHFC is a rare occurrence, its significance must not be overlooked given the subsequent risk of malignant transformation.

Six cases of CHFC have been identified at our institution over a 24 year time period. One of these cases showed extensive gastric metaplasia. In this report we aim to describe these six cases, as well as to provide a detailed review of the English literature regarding this rare diagnostic entity with a focus on metaplasia of the ciliated epithelial lining.

\section{Case Presentation Methods}

A search of the pathology database at our institution from 1989 to 2013 identified six cases of CHFC. Hematoxylin and eosin-stained slides and immunohistochemical stains (if performed) were reviewed for each case. The patient demographics, clinical presentation, imaging studies, and follow-up were obtained through available clinical records. This study received approval from the Human Resources and Protection (HRPO) Office and Institutional Review Board (IRB) Committee at Washington University.

\section{Clinical summary}

Clinicopathologic characteristics of the patients are summarized in Table 1. Four of the six patients were women and two were men, with ages ranging from 42 to 67 years (average 55 years). Only two patients were symptomatic at presentation, each initially presenting with right upper quadrant pain. One of these patients (Case 4) also developed jaundice due to biliary obstruction caused by the cyst; his laboratory values included elevated lipase (4540 Units/L, normal range 0-99 Units/L), amylase (1149 Units/L, normal range 28-100 Units/L), bilirubin (20.1 $\mathrm{mg} / \mathrm{dL}$, normal range 0.3-1.1 $\mathrm{mg} / \mathrm{dL}$ ), alkaline phosphatase (530 Units/L, normal range 38-126 Units/ L), aspartate transaminase (62 Units/L, normal range 11-47 Units/L), alanine transaminase (109 Units/L, normal range 7-53 Units/L), and CA19-9 (398.6 Units/mL, normal range 0-36 Units $/ \mathrm{mL}$ ), and CEA within normal limits $(1.0 \mathrm{ng} / \mathrm{mL}$, normal range $0-2.5 \mathrm{ng} / \mathrm{mL})$. Two additional patients had tumor marker serologies (Case 1, CA19-9; Case 6, CA19-9 and CEA) within normal limits, and the remaining three (Cases 2, 3,5) did not have these laboratory tests performed. Two patients had colorectal cancer, and their cysts were discovered incidentally during surgery. Five of the six cysts were surgically resected, one of which was only partially resected because the patient declined to undergo an additional procedure for complete enucleation. One patient underwent core biopsy followed by observation. One patient was presumed to have a mucinous cystic neoplasm of the pancreas after undergoing imaging studies and ultrasoundguided fine needle aspiration (FNA) biopsy performed at an outside institution (Case 6). Despite repeat imaging at our institution, it was only after the patient was taken to the operating room that the lesion was identified as originating from the porta hepatis of the liver, not the pancreas.

\section{Gross pathology}

Grossly, the cysts were tan-pink in color, with one cyst having green-brown plaques on the inner surface. They contained white to bloody contents; specifically, one contained thick, tan, mucoid material, one contained white material, and one had a small amount of attached thrombus. The cysts ranged in size from 0.7 to $17 \mathrm{~cm}$ in

Table 1 Six additional cases of ciliated hepatic foregut cysts

\begin{tabular}{|c|c|c|c|c|c|c|c|c|c|c|c|}
\hline Case & Age (yrs)/ sex & $\begin{array}{l}\text { Clinical } \\
\text { presentation }\end{array}$ & $\begin{array}{l}\text { Tumor } \\
\text { markers }\end{array}$ & Size $(\mathrm{cm})$ & Location & Locularity & Treatment & $\begin{array}{l}\text { Metaplasic } \\
\text { epithelium }\end{array}$ & Cyto/Bx & Follow-up & $\begin{array}{l}\text { Pertinent } \\
\text { history }\end{array}$ \\
\hline 1 & $42 / F$ & $\begin{array}{l}\text { PP epigastric } \\
\text { discomfort }\end{array}$ & WNL & $8 \times 4 \times 4$ & Porta hepatis & Uni & Resection & Gastric & $\mathrm{N}$ & LTFU & - \\
\hline 2 & $58 / F$ & Incidental & None & $0.7 \times 0.6 \times 0.5$ & $54 b$ & Uni & Resection & N & $\mathrm{N}$ & LTFU & $\begin{array}{l}\text { CRC with } \\
\text { liver mets }\end{array}$ \\
\hline 3 & $46 / F$ & Incidental & None & $1 \times 0.5 \times 0.3$ & Right liver & Uni & Observation & $N$ & $\mathrm{Bx}$ & Alive & CRC \\
\hline 4 & $66 / \mathrm{M}$ & $\begin{array}{l}\text { RUQ pain, } \\
\text { N/N, J, WL }\end{array}$ & $\uparrow C A 19-9$ & $17 \times 16 \times 15$ & S4 & Uni & $\begin{array}{l}\text { Partial } \\
\text { resection }\end{array}$ & $\mathrm{N}$ & $\mathrm{N}$ & Alive & - \\
\hline 5 & $50 / F$ & Incidental & None & $10 \times 5.5 \times 2$ & $N R$ & ${ }^{a}$ Uni & Resection & N & N & LTFU & - \\
\hline 6 & $67 / M$ & Incidental & WNL & $6.5 \times 4.0 \times 2.0$ & Porta hepatis & Uni & Resection & $\mathrm{N}$ & Cyto & Alive & $\begin{array}{l}\text { Presumed } \\
\text { pancreatic } \\
\text { head mass }\end{array}$ \\
\hline
\end{tabular}

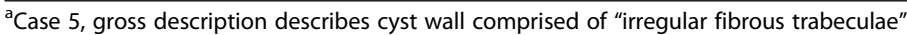

Bx biopsy; $C m$ centimeters; CRC concomitant colorectal cancer; Cyto cytology; F female; $J$ jaundice; LTFU lost to follow-up; $M$ male; Mets metastases; $N$ no; NR not reported; NN nausea/vomiting; PP post-prandial; RUQ right upper quadrant; $S$ segment (of liver); WL weight loss; WNL within normal limits; Uni unilocular; Yrs years 
greatest dimension (average $7.2 \mathrm{~cm}$ ). All six cysts were unilocular. Five cysts had smooth walls, and one had numerous "irregular fibrous trabeculae" in the wall.

\section{Microscopic pathology}

Histologic examination showed that five of the six cysts were entirely lined with simple, ciliated, cuboidal to columnar epithelium, surrounded by loose connective tissue, smooth muscle, and a poorly defined fibrous pseudocapsule (Fig. 1). Goblet cells containing mucin were identified in two of these cases (Figs. 1d-1f). Two cases showed marked pseudostratification of the ciliated epithelial lining (Figs. 1e-1f, 2d). In addition to focal areas with the classic epithelial lining, one case also showed areas with gastric metaplasia comprised of mucous glands and foveolar epithelium (Figs. 2a-2c). Immunohistochemistry showed the epithelial lining in this case was positive for keratin 7 and negative for CDX-2.

\section{Conclusions}

CHFC are increasingly reported hepatic lesions thought to be derived from the embryonic foregut that most frequently are identified in segment 4 of the liver, although a minority occur in the right lobe $[4,8]$. Over one hundred cases have been reported to date in the world literature, with bimodal reporting peaking in the late nineteenth century attributed to the popularity of autopsy and again in the late twentieth century with the increasing utilization and accuracy of radiologic studies [8]. A high number of cases have been reported in Japan;

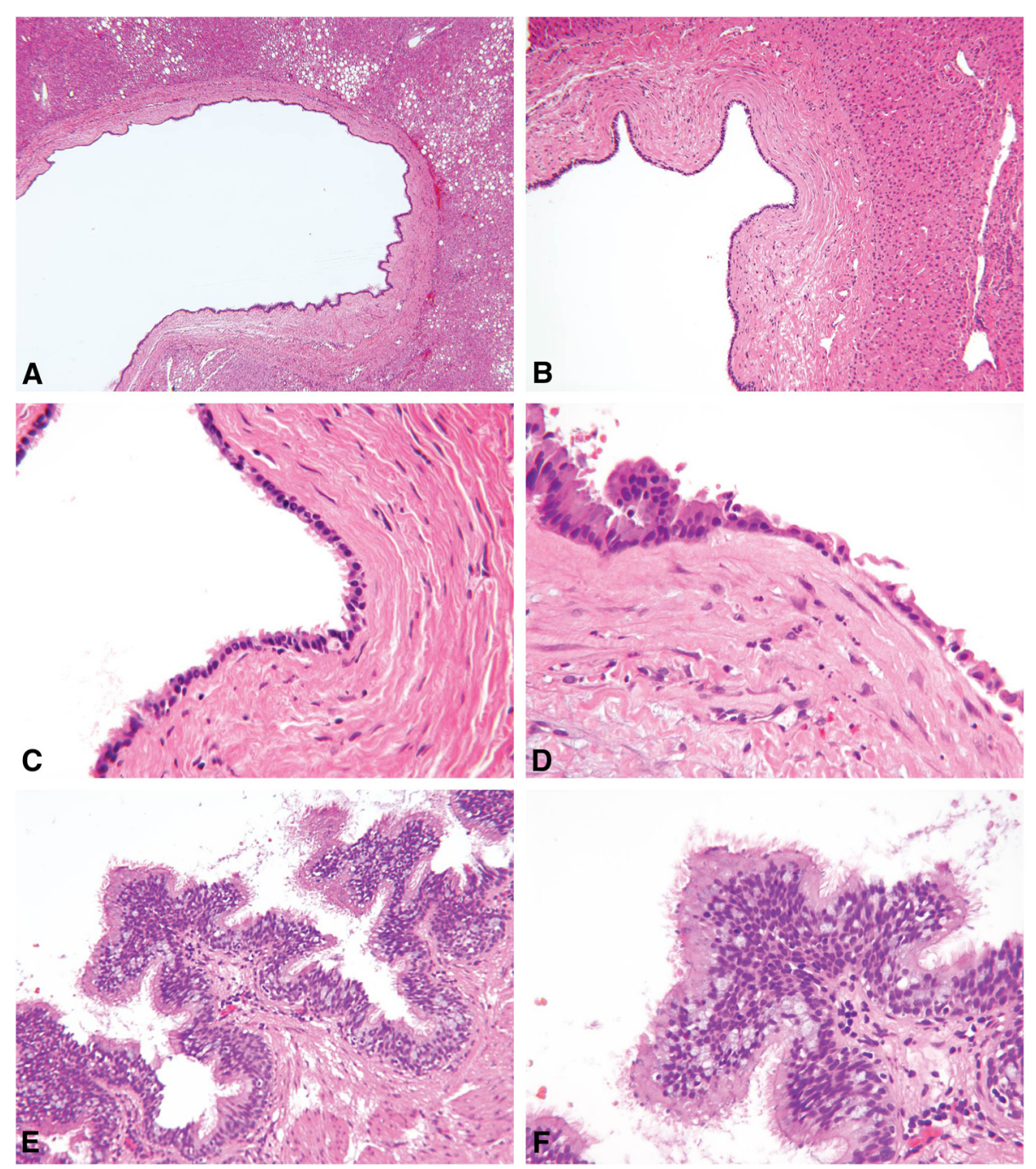

Fig. 1 CHFC, classic cases a Case 2, low power view highlights classic cyst architecture. b Case 3, CHFC is surrounded by a fibrous capsule and well-demarcated from the surrounding hepatic parenchyma. c Case 3, innermost layer may be completely or incompletely lined by cilia. $\mathbf{d}$ Case 4, rare goblet cells (black circle) mimicking respiratory tract mucosa may be seen. e Case 6, ciliated, pseudostratified epithelium. f Case 6, high power view shows pseudostratified, ciliated epithelium with abundant goblet cells (all images hematoxylin-eosin; original magnifications X40 [A], X100 $[B], X 200[E], X 400[C, D, F])$ 
A
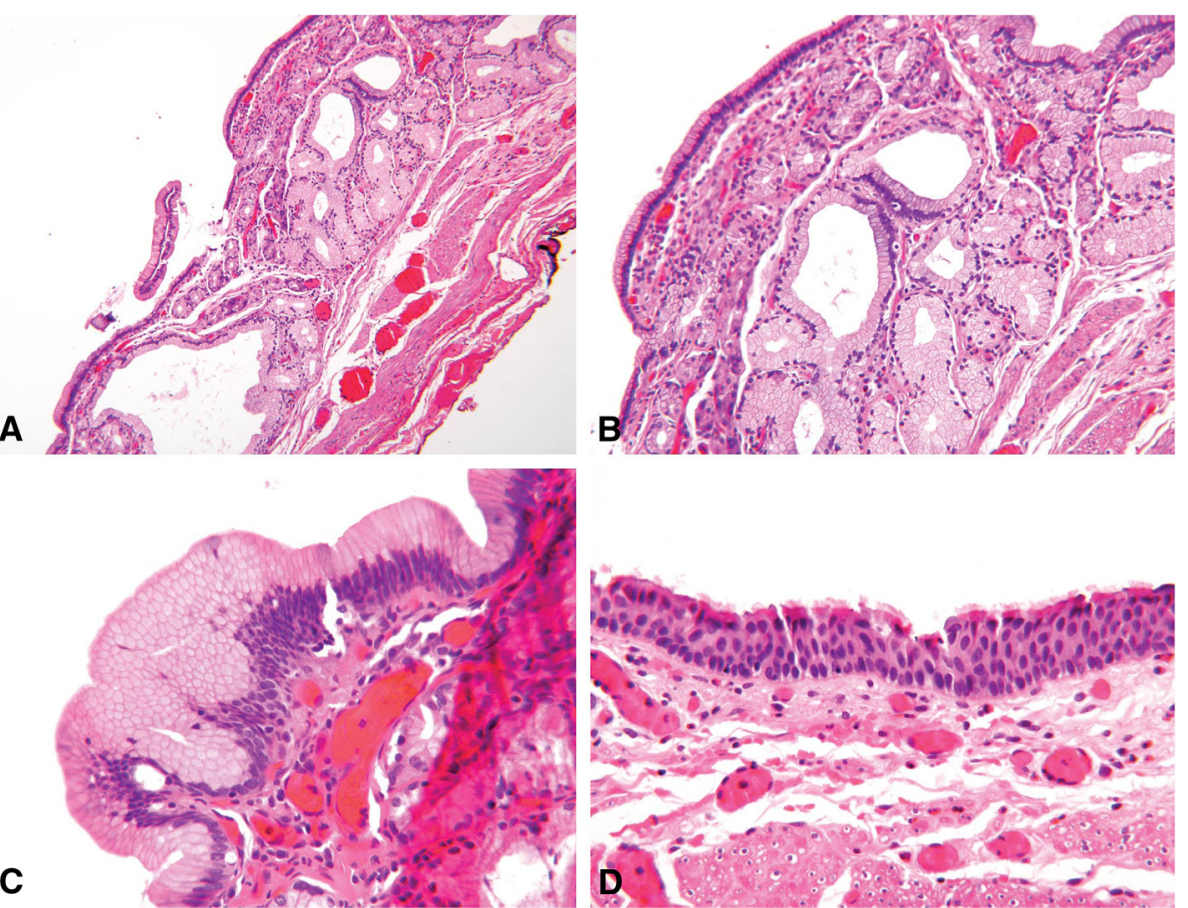

Fig. 2 CHFC with gastric metaplasia a Case 4, CHFC with gastric-type mucus-secreting glands in the submucosa. b Case 4, CHFC with branching mucous glands. c Case 4, surface foveolar-type epithelium. $\mathbf{d}$ Case 4, classic ciliated, pseudostratified, epithelial cyst lining (all images hematoxylin-eosin; original magnifications X100 [A], X200 [B], X400 [C, D])

it is unclear whether this is due to increased awareness or increased prevalence of this entity [8]. Radiologic findings associated with CHFC include a hypoechoic appearance on ultrasound and a hyperdense appearance on computed tomography (CT) scan [4].

The differential diagnosis for these lesions includes biliary cyst, simple cyst, parasitic cyst, mucinous cystic neoplasm (biliary cystadenoma), and various cystic metastases, such as cystic neuroendocrine tumor or necrotic metastases. Rarely, endometrial cysts may present as cystic lesions in women. In a child, an epidermoid cyst or a mesenchymal hamartoma are common possibilities [7]. When identified in the gallbladder fossa, a pancreatic pseudocyst, choledochal cyst, or gallbladder duplication should also be considered [20].

The classic histologic appearance of these lesions consists of 4 layers: a ciliated inner epithelial lining, loose connective tissue, smooth muscle, and a fibrous capsule [3]. Electron microscopy has confirmed the presence of goblet cells containing mucous vesicles and cilia lining the cysts composed of doublets of microtubules arranged in a $9+2$ pattern $[8,21]$. While some have suggested treatment with injection of sclerosing agents, surgical resection is generally the preferred method of treatment given the potential, albeit rare, for malignant transformation [4, 22, 23]. Interestingly, all of the malignant cases reported have shown squamous differentiation.
A review of the English literature showed 83 cases published to date, which are summarized in Additional file 1 [2, 4-59]. Patients ranged from 20 weeks gestational age to 82 years with a slight female predominance (41 female, 38 male, 4 not reported). The lesions were most commonly discovered incidentally. Tumor marker serologies (CA19-9, CEA, and/or AFP) were performed in 17 cases and were elevated in 6 of $(35.3 \%, 6 / 17)$. All of the cases with elevated tumor marker serologies had benign histologic features and no evidence of metaplasia. The cysts were most commonly unilocular, with sizes ranging from $0.6 \mathrm{~cm}$ to $19.3 \mathrm{~cm}$ (average $4.5 \mathrm{~cm}$ ). Patients were most frequently treated with surgical resection. Core biopsy was performed in 6 cases $(4 / 6,66.7 \%$ diagnostic) and FNA biopsy was performed in 12 cases (9/12, $75 \%$ diagnostic).

Twelve cases $(14.5 \%, 12 / 83)$ had histologic evidence of metaplastic epithelium lining the inner cyst wall [7, 9-19, 33]. Eleven of these cases had squamous metaplasia, 5 of which also reported squamous cell carcinoma, presumably due to malignant transformation of the metaplastic squamous epithelium $[6,8-11$, 13-18]. One case had concomitant squamous cell carcinoma as well as gastric antral metaplasia, and one case had only gastric metaplasia $[16,33]$. Tumor marker serologies were performed in 4 of the metaplastic/malignant cases ( 3 squamous cell carcinoma, 1 squamous 
metaplasia), and all were within normal limits $[10,13$, 15, 17]. Our series reports the third case of gastric metaplasia arising within a CHFC, and it is the second known case of gastric metaplasia in CHFC not associated with malignancy.

In conclusion, CHFC is a rare entity with 89 cases reported to date in the English literature, including the 6 cases from the current study. All cases from this series demonstrated the classical histologic features, with the cyst wall comprised of 4 distinct layers. While the inner epithelial lining is most commonly ciliated and pseudostratified, rare cases with squamous metaplasia, squamous carcinoma, and/or gastric metaplasia have been reported. Interestingly, tumor serologies were elevated in a minority of benign cases and showed no correlation with metaplasia or malignant transformation. This rare diagnostic entity should be included in the differential diagnosis of cystic liver lesions, and complete surgical excision should be recommended given the potential for metaplastic or malignant squamous carcinoma and the inability to monitor disease progression.

\section{Consent}

A waiver of informed consent was granted from the HRPO Office and IRB Committee at Washington University due to the fact that this is a retrospective case series and no changes were made to patient management as a result of this study. The Washington University HRPO/IRB Committee is willing to provide written documentation confirming their decision for review by the Editor-in-Chief of this journal.

\section{Additional file}

Additional file 1: Review of ciliated hepatic foregut cysts previously reported in the English literature. Table containing all cases of ciliated hepatic foregut cyst published to date in the English literature. Data includes patient demographics, clinical features, location, treatment, metaplasia, if biopsy or fine needle aspiration was performed, and tumor serologic markers.

\section{Abbreviations}

CHFC: Ciliated hepatic foregut cyst; CT: Computed tomography: HRPO: Human resources and protection office; IRB: Institutional review board; FNA: Fine needle aspiration.

\section{Competing interests}

The authors declare that they have no competing interests.

\section{Authors' contributions}

$K C B, C M P, M B R$, and $E M B$ conducted the project. $K C B$ and $C M P$ performed data collection, a search of the literature, and drafted the initial manuscript. $M B R$ and EMB conceived the project and provided guidance, editing, expert knowledge.

\section{Acknowledgements}

A portion of this study was presented as a poster at CAP '14: The

Pathologists' Meeting in Chicago, IL.

\section{Author details}

'Washington University School of Medicine, 660 South Euclid Avenue, Saint Louis, MO 63110, USA. ${ }^{2}$ Department of Obstetrics and Gynecology, Duke University School of Medicine, 40 Duke Medicine Cir \#1J, Durham, NC 27710, USA. ${ }^{3}$ Department of Pathology and Immunology, Washington University School of Medicine, Campus Box 8118, 660 South Euclid Avenue, Saint Louis, MO 63110, USA.

Received: 22 January 2015 Accepted: 10 June 2015

Published online: 30 June 2015

\section{References}

1. Sharma S, Dean AG, Corn A, et al. Ciliated hepatic foregut cyst: an increasingly diagnosed condition. Hepatobiliary Pancreat Dis Int. 2008;7:581-9.

2. Wheeler DA, Edmondson HA. Ciliated hepatic foregut cyst. Am J Surg Pathol. 1984;8:467-70.

3. Goodman ZD, Kleiner DE. Tumours and tumour-like lesions of the liver. In: Burt AD, Portmann BC, Ferrell LD, editors. MacSween's pathology of the liver. 5th ed. China: Churchill Livingstone Elsevier; 2007. p. 761-851.

4. Ambe C, Gonzalez-Cuyar L, Farooqui S, et al. Ciliated hepatic foregut cyst: 103 cases in the world literature. Op J Path. 2012;2:45-9.

5. Oida T, Mimatsu K, Kawasaki A, et al. Laparoscopic excision for an enlarged ciliated hepatic foregut cyst as a minimally invasive procedure. J Laparoendosc Adv Surg Tech A. 2009;19:203-6.

6. Young AS, Nicol KK, Teich S, et al. Catheter-based drainage and agitation for definitive cytological diagnosis of a ciliated hepatic foregut cyst in a child. Pediatr Dev Pathol. 2007;10:153-6.

7. Stringer $\mathrm{MD}$, Jones $\mathrm{MO}$, Woodley $\mathrm{H}$, et al. Ciliated hepatic foregut cyst. J Pediatr Surg. 2006;41:1180-3.

8. Vick DJ, Goodman ZD, Deavers MT, et al. Ciliated hepatic foregut cyst: a study of six cases and review of the literature. Am J Surg Pathol. 1999;23:671-7.

9. Khoddami M, Kazemi Aghdam M, Alvandimanesh A. Ciliated hepatic foregut cyst: two case reports in children and review of the literature. Case Rep Med. 2013;2013:372017.

10. Wilson JM, Groeschl R, George B, et al. Ciliated hepatic cyst leading to squamous cell carcinoma of the liver - A case report and review of the literature. Int J Surg Case Rep. 2013;4:972-5.

11. Guérin F, Hadhri R, Fabre M, et al. Prenatal and postnatal ciliated hepatic foregut cysts in infants. J Pediatr Surg. 2010;45:E9-14.

12. Deshmukh SD, Pathak GS, Joshi AR, et al. Ciliated hepatic foregut cyst. Indian J Pathol Microbiol. 2009:52:598-9.

13. Zhang $X$, Wang Z, Dong Y. Squamous cell carcinoma arising in a ciliated hepatic foregut cyst: case report and literature review. Pathol Res Pract. 2009:205:498-501.

14. Rogers TN, Woodley H, Ramsden W, et al. Solitary liver cysts in children: not always so simple. J Pediatr Surg. 2007:42:333-9.

15. Ben Mena N, Zalinski S, Surcek M, et al. Ciliated hepatic foregut cyst with extensive squamous metaplasia: report of a case. Virchows Arch. 2006:449:730-3.

16. de Lajarte-Thirouard AS, Rioux-Leclercq N, Boudjema K, et al. Squamous cell carcinoma arising in a hepatic forgut cyst. Pathol Res Pract. 2002;198:697-700.

17. Furlanetto A, Dei Tos AP. Squamous cell carcinoma arising in a ciliated hepatic foregut cyst. Virchows Arch. 2002;441:296-8.

18. Vick DJ, Goodman ZD, Ishak KG. Squamous cell carcinoma arising in a ciliated hepatic foregut cyst. Arch Pathol Lab Med. 1999:123:1115-7.

19. Harty MP, Hebra A, Ruchelli ED, et al. Ciliated hepatic foregut cyst causing portal hypertension in an adolescent. AJR Am J Roentgenol. 1998;170:688-90.

20. Rodriguez E, Soler R, Fernandez P. MR imaging findings of ciliated hepatic foregut cyst: an unusual cause of fluid-fluid level within a focal hepatic lesion (2005.4b). Eur Radiol. 2005;15:1499-501.

21. Terada T, Nakanuma Y, Kono N, et al. Ciliated hepatic foregut cyst. A mucus histochemical, immunohistochemical, and ultrastructural study in three cases in comparison with normal bronchi and intrahepatic bile ducts. Am J Surg Pathol. 1990;14:356-63.

22. Kaplan KJ, Escobar M, Alonzo M, et al. Ciliated hepatic foregut cyst: report of a case on fine-needle aspiration. Diagn Cytopathol. 2007;35:245-9.

23. De J, Rossman L, Kott MM, et al. Cytologic diagnosis of ciliated hepatic foregut cyst. Diagn Cytopathol. 2006:34:846-9.

24. Fernández-Aceñero MJ, Corral JL, Manzarbeitia F. Ciliated hepatic foregut cyst: two further cases with an immunohistochemical analysis. Hepatogastroenterology. 2012;59:1260-2. 
25. Yang JD, Moon WS. Ciliated hepatic foregut cyst. Korean J Hepatol. 2012;18:98-100

26. Fujita AW, Steelman CK, Abramowsky CR, et al. Ciliated hepatic foregut cyst: four case reports with a review of the literature. Pediatr Dev Pathol. 2011;14:418-21.

27. Shimokawa K, Kenfield C, Thomson B. Ciliated foregut cyst of the liver mimicking a hydatid. ANZ J Surg. 2011:81:847-8.

28. Zaydfudim V, Rosen MJ, Gillis LA, et al. Ciliated hepatic foregut cysts in children. Pediatr Surg Int. 2010;26:753-7.

29. Goodman MD, Mak GZ, Reynolds JP, et al. Laparoscopic excision of a ciliated hepatic foregut cyst. JSLS. 2009;13:96-100.

30. Betalli P, Gobbi D, Talenti E, et al. Ciliated hepatic foregut cyst: from antenatal diagnosis to surgery. Pediatr Radiol. 2008;38:230-2.

31. Geramizadeh B, Salehzadeh A, Nikeghbalian S. Ciliated hepatic foregut cyst mimicking a hydatid cyst: a case report and review of literature. Saudi J Gastroenterol. 2008;14:142-3.

32. Kiyochi H, Okada K, Iwakawa K, et al. Ciliated hepatic foregut cyst with obstructive jaundice. Case Rep Gastroenterol. 2008;2:479-85.

33. Lubrano J, Rouquette A, Huet E, et al. Ciliated hepatic foregut cyst discovered after kidney transplantation in a hepatitis $C$ virus-infected patient: a report of one case and review of the literature. Eur J Gastroenterol Hepatol. 2008;20:359-61.

34. Shaw JM, Krige JE, Beningfield SJ, et al. Ciliated hepatic foregut cyst: a rare cystic liver lesion. J Gastrointest Surg. 2008;12:1304-6.

35. Kang CM, Ahn SG, Kim HK, et al. Laparoscopic excision of ciliated hepatic foregut cyst: a first report in Korea. Surg Laparosc Endosc Percutan Tech. 2006;16:255-8

36. Sato Y, Kitagawa S, Zen Y, et al. Ciliated hepatic cyst without smooth muscle layer: a variant of ciliated hepatic foregut cyst? Pathol Int. 2006;56:340-4

37. Straus T, Osipov V. Ciliated hepatic foregut cyst in a patient with renal cell carcinoma. BMC Cancer. 2006;6:244

38. Fang SH, Dong DJ, Zhang SZ. Imaging features of ciliated hepatic foregut cyst. World J Gastroenterol. 2005;11:4287-9.

39. Kim S, White FV, McAlister W, et al. Ciliated hepatic foregut cyst in a young child. J Pediatr Surg. 2005;40:e51-53.

40. Koletsa T, Tzioufa V, Michalopoulos A, et al. Ciliated hepatic foregut cyst communicating with the gallbladder. Virchows Arch. 2005;446:200-1.

41. Cai XJ, Huang DY, Liang $X$, et al. Ciliated hepatic foregut cyst: report of first case in China and review of literature. J Zhejiang Univ (Sci). 2004;5:483-5.

42. Jakowski JD, Lucas JG, Seth S, et al. Ciliated hepatic foregut cyst: a rare but increasingly reported liver cyst. Ann Diagn Pathol. 2004;8:342-6.

43. Momin TA, Milner R, Sarmiento JM. Ciliated hepatic foregut cyst of the left hepatic vein. J Gastrointest Surg. 2004;8:601-3.

44. del Poggio P, Jamoletti C, Mattiello M, et al. Images in Hepatology. Ciliated hepatic foregut cyst J Hepatol. 2003;39:1090

45. Horii T, Ohta M, Mori T, et al. Ciliated hepatic foregut cyst. A report of one case and a review of the literature. Hepatol Res. 2003;26:243-8.

46. Bogner B, Hegedûs G. Ciliated hepatic foregut cyst. Pathol Oncol Res. 2002;8:278-9.

47. Hirata M, Ishida H, Konno K, et al. Ciliated hepatic foregut cyst: case report with an emphasis on US findings. Abdom Imaging. 2001;26:594-6.

48. Chatelain D, Chailley-Heu B, Terris B, et al. The ciliated hepatic foregut cyst, an unusual bronchiolar foregut malformation: a histological, histochemical, and immunohistochemical study of 7 cases. Hum Pathol. 2000;31:241-6.

49. Wu ML, Abecassis MM, Rao MS. Ciliated hepatic foregut cyst mimicking neoplasm. Am J Gastroenterol. 1998;93:2212-4.

50. Carnicer J, Durán C, Donoso L, et al. Ciliated hepatic foregut cyst. J Pediatr Gastroenterol Nutr. 1996;23:191-3.

51. Hornstein A, Batts KP, Linz LJ, et al. Fine needle aspiration diagnosis of ciliated hepatic foregut cysts: a report of three cases. Acta Cytol. 1996;40:576-80.

52. Murakami T, Imai A, Nakamura $\mathrm{H}$, et al. Ciliated foregut cyst in cirrhotic liver. J Gastroenterol. 1996:31:446-9.

53. Shoenut JP, Semelka RC, Levi C, et al. Ciliated hepatic foregut cysts: US, CT, and contrast-enhanced MR imaging. Abdom Imaging. 1994;19:150-2.

54. Zaman SS, Langer JE, Gupta PK. Ciliated hepatic foregut cyst. Report of a case with findings on fine needle aspiration. Acta Cytol. 1995;39:781-4.

55. Terada T, Nakanuma Y, Ohta T, et al. Mucin-histochemical and immunohistochemical profiles of epithelial cells of several types of hepatic cysts. Virchows Arch A Pathol Anat Histopathol. 1991;419:499-504.
56. Kadoya M, Matsui O, Nakanuma Y, et al. Ciliated hepatic foregut cyst: radiologic features. Radiology. 1990;175:475-7.

57. Kimura A, Makuuchi M, Takayasu K, et al. Ciliated hepatic foregut cyst with solid tumor appearance on CT. J Comput Assist Tomogr. 1990;14:1016-8.

58. Dardik H, Glotzer P, Silver C. Congenital hepatic cyst causing jaundice: report of a case and analogies with respiratory malformations. Ann Surg. 1964;159:585-92.

59. Dockerty MB, Gray HK, Henson Jr SW. Benign tumors of the liver. III Solitary cysts Surg Gynecol Obstet. 1956;103:607-12.

\section{Submit your next manuscript to BioMed Central and take full advantage of:}

- Convenient online submission

- Thorough peer review

- No space constraints or color figure charges

- Immediate publication on acceptance

- Inclusion in PubMed, CAS, Scopus and Google Scholar

- Research which is freely available for redistribution 